\title{
ANALISIS BUSINESS MODEL CANVAS PADA SYAHIDA INN DALAM MENCARI ALTERNATIF STRATEGI BISNIS BADAN LAYANAN UMUM UIN SYARIF HIDAYATULLAH JAKARTA
}

\author{
ADY CAHYADI ${ }^{1}$ \\ ANWAR SALAHUDDIN ${ }^{2}$ \\ 12 Fakultas Ekonomi dan Bisnis, UIN Syarif Hidayatullah Jakarta \\ 1adycahyadi@uinjkt.ac.id
}

\begin{abstract}
The development of the hotel sector in the pandemic covid-19 currently decrease so as prosecuting the business doers to survive and grow the business including Syahida Inn as a business units of Syarif Hidayatullah Jakarta The State Islamic University (UIN Jakarta). Therefore it is need of a business model exact to Syahida Inn knows how to run effectively, efficient, and economical. The purpose of this research is to develop the business model in the future. The kind of research is descriptive qualitative with bussiness model canvas (BMC) and strenght weakness opportunity threat (SWOT) approach. The result showed that the creation of value propositions in the future is sharia hotel, meeting room, wedding hall, cafe and restaurant with convenience, comfortable and hospitality in order will affect every element business model canvas there is an increase in the primary resource, owned the key activity, revenue streams, and increase the cooperation partners. The element of cost structure occured additional cost in promotion while on a customer segment focus to individual and government institutions. SWOT Analysis showed, Syahida Inn is in the first quadrant mean are in progressive strategy with the main focus on market penetration by increasing the promotion either online or offline, focus on market development with the introduction of products to the Tangerang Raya, Province of Banten and Province of Jakarta, and the latter focus on the product development by increasing the meeting facilities, wedding hall, cafe/restaurant, fitness center, and the auditorium/theatre room.
\end{abstract}

Keywords: Business Model Canvas, Hotel Industry, SWOT

Abstrak: Perkembangan sektor perhotelan di masa pandemi covid-19 saat ini mengalami penurunan drastis sehingga menuntut masing-masing pelaku usaha di sektor ini untuk terus bertahan seraya menumbuhkembangkan bisnisnya, termasuk Syahida Inn sebagai salah satu unit bisnis milik Badan Layanan Umum UIN Syarif Hidayatullah Jakarta yang berlokasi di Ciputat Tangerang Selatan. Untuk itu dibutuhkan model bisnis yang tepat agar Syahida Inn dapat mengetahui bagaimana menjalankan aktivitas operasionalnya secara efektif, efisien dan ekonomis. Tujuan dari penelitian ini adalah merancang model bisnis di masa yang akan datang sebagai langkah bertahan dan berkembang bagi Syahida Inn. Jenis penelitian adalah kualitatif deskriptif dengan pendekatan model bisnis kanvas (BMC) yang dilengkapi dengan analisis Strenght Weakness Opportunity Threat (SWOT). Hasil penelitian menunjukkan bahwa penciptaan proposisi nilai di masa datang berupa penginapan syariah, ruang meeting, ruang serbaguna dan cafe yang mengedepankan kemudahan, keramahan, dan kenyamanan dalam pemesanan akan memengaruhi setiap elemen bisnis model canvas, yaitu terjadi penambahan dalam sumber daya utama yang dimiliki, aktivitas kunci yang dilakukan, aliran pendapatan yang masuk dan penambahan pada mitra kerjasama. Dalam elemen struktur biaya yang dikeluarkan terjadi penambahan biaya dalam hal sosialisasi dan promosi sementara pada elemen customer segment fokus utama ditujukan pada individu-individu dan instansi pemerintah. Hasil analisis SWOT, posisi Syahida Inn berada pada kuadran I yang berarti berada pada posisi strategi progresif dengan fokus utama pada penetrasi pasar melalui peningkatan kegiatan promosi baik online maupun offline, fokus pada pengembangan pasar melalui pengenalan produk jasa layanan ke wilayah Tangerang Raya dan Propinsi Banten, dan yang terakhir fokus pada pengembangan produk melalui peningkatan fasilitas ruang meeting, aula serbaguna, cafe/restoran, fitness center, dan auditorium.

Kata Kunci. Bisnis Model Kanvas, Industri Hotel, SWOT 


\section{PENDAHULUAN}

Industri pariwisata dan khususnya perhotelan merupakan salah satu industri pendorong dan penggerak perekonomian dunia beberapa tahun belakangan. Namun saat ini, ditengah dunia dihadapkan pada pandemi global covid-19 sejak akhir tahun 2019, industri pariwisata dan perhotelan juga menjadi industri dengan risiko yang sangat tinggi dibanding industri penggerak perekonomian lainnya. Berdasarkan data dari Perhimpunan Hotel dan Restoran Indonesia (PHRI) terdapat 1.642 hotel yang tutup akibat dampak pandemi covid-19, sementara tingkat kerugian diperkirakan mencapai Rp.60 Trilyun sampai awal April 2020 (Diayudha, 2020). Sebaran hotel yang tutup menurut PHRI (awal April 2020).

\section{Tabel 1 Sebaran Hotel yang Tutup}

\begin{tabular}{lll}
\hline No & Provinsi & Jumlah \\
\hline 1 & Jawa Barat & 581 \\
2 & Bali & 201 \\
3 & DKI Jakarta & 100 \\
4 & Provinsi Lainnya & 760 \\
\hline \multicolumn{3}{l}{ Sumber: Perhimpunan Hotel dan Restoran Indonesia (2020) }
\end{tabular}

Lesunya industri pariwisata dan perhotelan sejalan dengan menurunnya kunjungan wisatawan mancanegara pada periode merebaknya pandemi covid 19 di Indonesia. Kementerian Pariwisata dan Ekonomi Kreatif mencatat penurunan kunjungan wisatawan mancanegara pada bulan April 2020 sebesar 87,44\% dibandingkan dengan bulan April 2019.

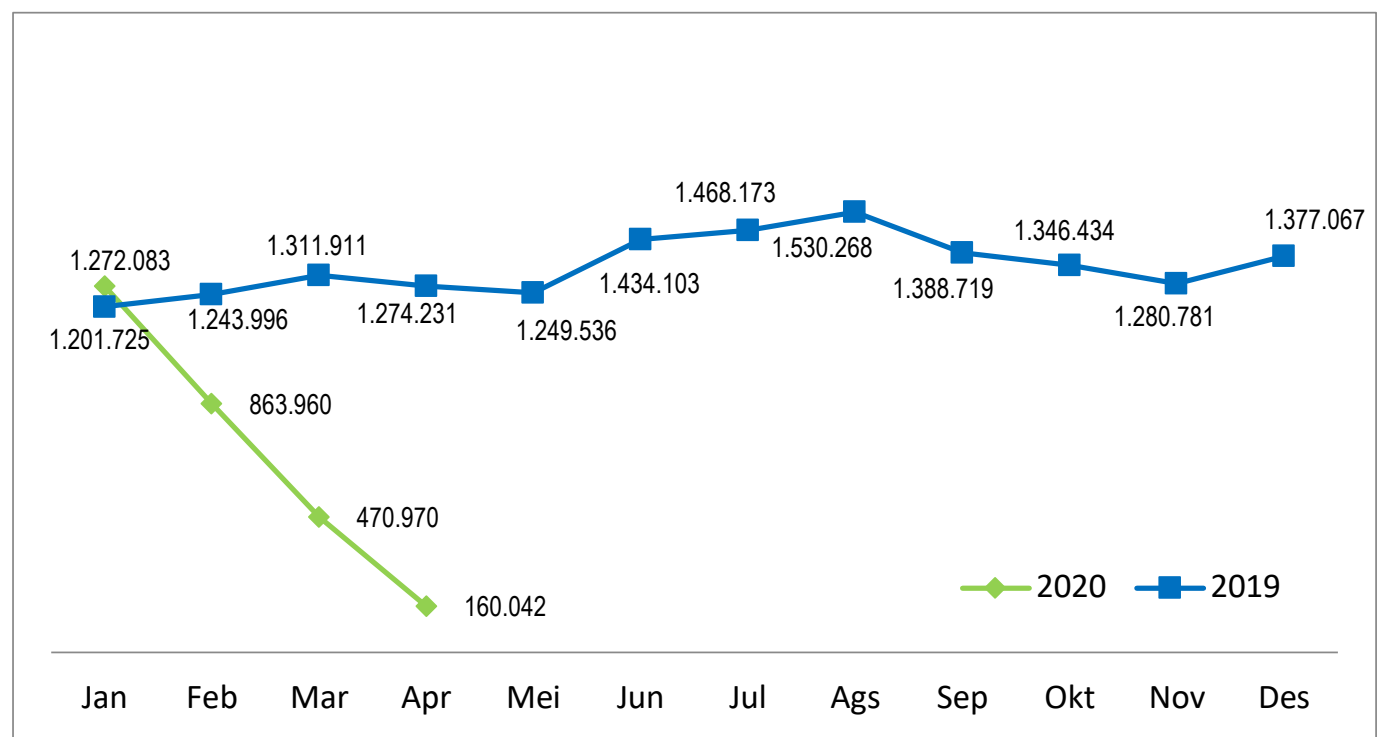

Sumber: BPS diolah kembali oleh Pusat Data dan Sistem Informasi (2019)

\section{Gambar 1 Kunjungan Bulanan Wisatawan Mancanegara}

Menurunnya kunjungan wisatawan secara langsung berdampak pada tingkat hunian kamar hotel (okupansi) dimana banyak hotel yang hanya memiliki tingkat okupansi single digit atau bahkan $0 \%$ (Diayudha, 2020). Dampak penurunan juga dirasakan Syahida Inn, salah satu hotel non bintang milik Badan Layanan Umum (BLU) UIN Syarif Hidayatullah Jakarta. Semenjak penerapan Pembatasan Sosial Berskala Besar (PSBB) di Kota Tangerang Selatan, operasional Syahida Inn dihentikan untuk sementara waktu demi menjaga risiko penyebaran pandemi covid 19. Untuk mengurangi dampak penurunan dan mencoba menapaki pertumbuhan kembali diperlukan strategi bisnis yang tepat yang harus diambil oleh manajemen Syahida Inn. 
Syahida Inn berdiri pada tahun 2003 sebagai bagian dari transisi perubahan IAIN menjadi UIN yang dimulai pada tahun 2000 silam. Syahida Inn dibangun untuk memenuhi kebutuhan fasilitas penginapan dan rapat bagi sivitas akademika UIN Syarif Hidayatullah Jakarta atau Kementerian Agama pada umumnya, terdiri dari 3 (tiga) ruang rapat, 54 kamar (VIP dan Standar), 1 (satu) aula serbaguna, dan 1 (satu) auditorium yang mampu menampung 700 peserta undangan. Dalam perkembangan usahanya, Syahida Inn secara stabil mampu berkontribusi dengan baik terhadap Pendapatan Negara Bukan Pajak (PNBP) BLU UIN Syarif Hidayatullah Jakarta. Pada tahun 2016 Syahida Inn mampu membukukan PNBP sebesar Rp.2.915.910.520,- kemudian turun pada tahun 2017 menjadi Rp.2.602.316.500,- beranjak naik pada tahun 2018 menjadi Rp.2.731.920.000,- dan kembali naik signifikan pada tahun 2019 menjadi Rp.3.108.241.124,-.

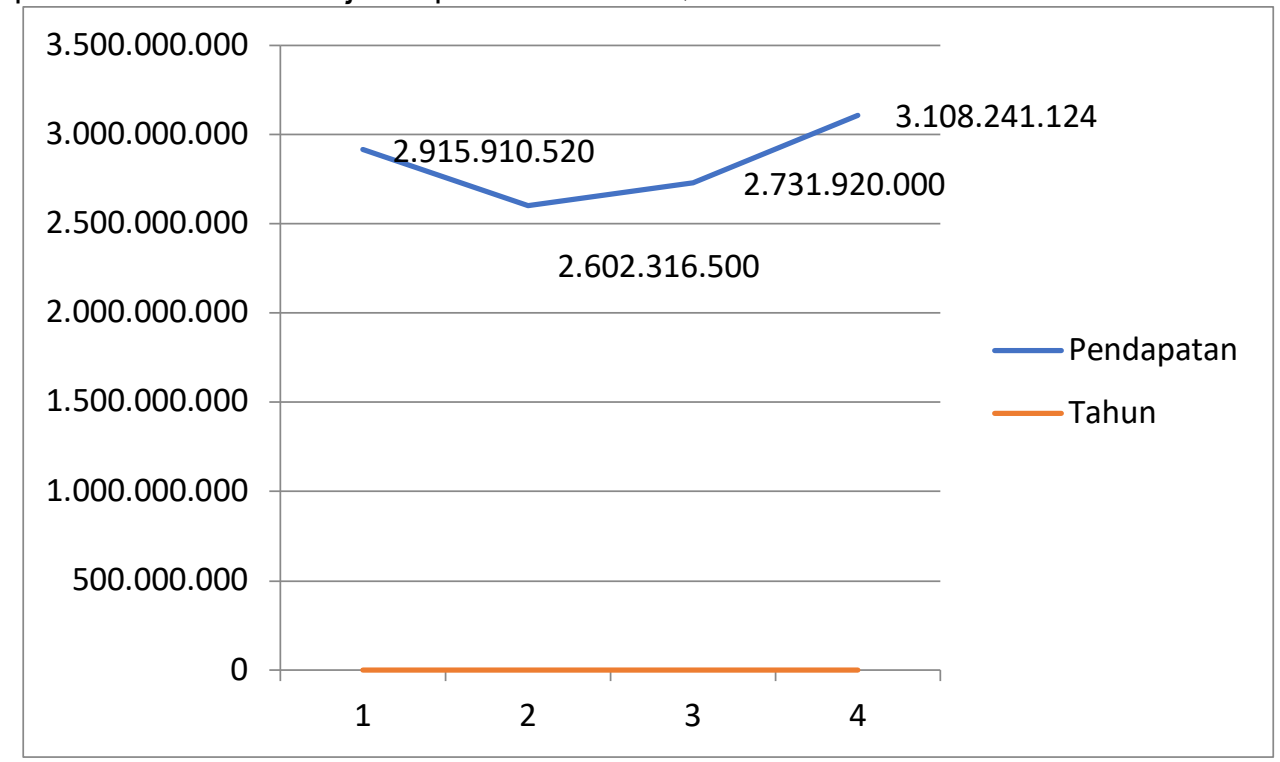

Sumber: diolah dari laporan tahunan Syahida Inn(2020)

Gambar 2 Trend Pendapatan Negara Bukan Pajak (PNBP) dari Syahida Inn

Perpanjangan PSBB Kota Tangerang Selatan yang kelima kalinya dan berakhir pada 12 Juli 2020 akan berdampak terhadap PNBP Syahida Inn kepada BLU UIN Syarif Hidayatullah Jakarta. Jumlah setoran PNBP pada semester 1 tahun 2020 belum mencapai Rp.500.000.000,-- Hal tersebut menandakan dampak besar pandemi covid 19 terhadap aktivitas bisnis Syahida Inn. Sebagaimana diketahui UIN Syarif Hidayatullah Jakarta bertransisi status pengelolaan keuangannya menjadi Badan Layanan Umum (BLU) sejak tahun 2008 melalui Keputusan Menteri Keuangan Nomor 42 Tahun 2008. Perubahan status menjadi BLU bertujuan untuk meningkatkan pelayanan kepada masyarakat, selain itu BLU juga diharapkan mampu mencari dan mengelola potensi Pendapatan Negara Bukan Pajak (PNBP) yang selanjutnya akan menjadi pendapatan yang dikelola oleh BLU itu sendiri dengan menerapkan praktek bisnis yang sehat. Dalam prakteknya tidak semua satuan kerja (satker) dibawah Kementerian/Lembaga dapat menjadi BLU, karena hanya satker yang memenuhi persyaratan substantif, teknis dan administratif saja yang berhak menyandang status BLU. Berdasarkan Peraturan Pemerintah Nomor 23 Tahun 2005 Jo Peraturan Pemerintah Nomor 74 Tahun 2012 Tentang Pengelolaan Keuangan Badan Layanan Umum menyebutkan persyaratan yang harus dipenuhi untuk menjadi Satuan Kerja BLU antara lain persyaratan substantif yakni apabila instansi pemerintah atau satker tersebut menyelenggarakan layanan umum yang berhubungan dengan penyediaan barang/jasa layanan umum, pengelolaan wilayah/kawasan, pengelolaan dana khusus dalam rangka meningkatkan ekonomi atau pelayanan kepada masyarakat. Selanjutnya persyaratan teknis, persyaratan teknis terpenuhi apabila 
kinerja layanan di bidang tugas pokok dan fungsinya layak dikelola dan ditingkatkan pencapaiannya melalui BLU sebagaimana direkomendasikan oleh Kementerian/Lembaganya dan memiliki kinerja keuangan yang sehat, terakhir persyaratan administratif. Persyaratan administratif terpenuhi apabila satker yang bersangkutan dapat menyajikan dokumen-dokumen, antara lain: pernyataan kesanggupan meningkatkan kinerja layanan, pola tata kelola, rencana strategis bisnis, laporan keuangan pokok, standar pelayanan minimum, dan laporan audit terakhir atau pernyataan kesediaan untuk diaudit independen. Berdasarkan persyaratan yang telah disebukan diatas maka tidak mudah untuk berubah menjadi BLU.

Badan Layanan Umum (BLU) sebagai penyelenggara pelayanan publik berperan penting dalam memberikan layanan kepada masyarakat berupa penyediaan barang dan/atau jasa. Secara yuridis BLU bukan merupakan badan hukum, namun BLU beroperasi sebagai unit kerja kementerian negara untuk tujuan pemberian layanan umum yang pengelolaannya berdasarkan kewenangan yang didelegasikan oleh instansi induk yang bersangkutan. Oleh karena itu maka pengelolaan keuangannya tidak terpisah dari kementerian negara/lembaga/pemerintah daerah sebagai instansi induknya (Juliani, 2018). Dalam mendukung instansi induknya maka Syahida Inn yang bergerak dalam penyediaan fasilitas penginapan, ruang meeting, cafe/resto dan lain sebagainya diharapkan mampu menghasilkan pendapatan sehingga dapat meningkatkan pendapatan instansi induk dari praktek bisnis yang telah dijalankan.

Melihat besarnya dampak pandemi covid 19 terhadap aktivitas bisnis Syahida Inn, maka diperlukan satu konsep model bisnis yang dapat digunakan untuk merumuskan strategi pengembangan usaha yang berkelanjutan. Kepopuleran konsep model bisnis di mulai sejak tahun 1990 ke atas ketika internet mulai banyak membahas tentang konteks model bisnis dalam sebuah perusahaan dan bagaimana perubahan lingkungan. Konsep Model bisnis digunakan sebagai cara untuk menjelaskan tentang dasar pemikiran bagaimana suatu organisasi menciptakan, memberikan, dan menangkap nilai suatu perusahaan (Wardhanie \& Kumalawati, 2018). Analisa model bisnis ini akan memberikan suatu keuntungan bagi perusahaan agar dapat semakin berkembang. Salah satu konsep bisnis yang digunakan adalah Business Model Canvas (BMC) (Alexander Osterwalder, 2013). Business Model Canvas (BMC) adalah bahasa yang sama dalam sebuah model bisnis untuk menggambarkan, memvisualisasikan, menilai, dan mengubah model bisnis dalam satu lembar canvas. Penggunaan BMC sekarang telah berkembang untuk memandu proses penilaian dalam memeriksa pola proses transformasi pengembangan bisnis (Permatasari \& Maureen Nuradhi, 2020).

Dalam buku yang berjudul Business Model Generation karangan Alexander Osterwalder (2013) menyatakan bahwa menganalisa keseluruhan model bisnis memang penting, namun memperhatikan komponen-komponennya secara mendetil, juga dapat membuka jalan baru untuk inovasi dan pembaharuan. Business Model Canvas memiliki konsep sembilan elemen, antara lain (Wardhani, 2017): 1) Customer Segment, masyarakat yang menggunakan jasa/produk dari organisasi dan mereka yang berkontribusi dalam memberikan penghasilan bagi organisasi, segmentasi pelanggan juga dapat dipilah berdasarkan perilaku, umur, profesi, penghasilan dan geografi. 2) Value Proposition, memberi tawaran untuk memecahkan masalah pelanggan dan semaksimal mungkin memenuhi keinginan pelanggan. 3) Channels, sebuah elemen seperti komunikasi, distribusi dan saluran penjualan yang menyatakan bagaimana cara organisasi berkomunikasi dengan pelanggan segmennya dan menyampaikan value proposition-nya. 4) Customer Relationship, pembinaan hubungan dengan pelanggan dengan tujuan untuk mendapatkan pelanggan baru dan mempertahankan pelanggan lama. 5) Key Activities, merupakan kegiatan utama yang menunjang keberhasilan suatu model bisnis dalam mengirimkan value propotitionsnya kepada pelanggan. 6) Key Resources, menggambarkan aset-aset terpenting yang menentukan keberhasilan pengoperasian model bisnis, seperti bangunan, kendaraan, intelektual dan tenaga kerja. 7) Key Partnership, suatu kesepakatan kerja sama bisnis yang diprakarsai secara sukarela antara dua atau 
lebih perusahaan untuk menyelesaikan proyek tertentu. Kerjasama ini dapat menimbulkan penghematan biaya, mengurangi resiko dan memperoleh sumber daya yang tidak dimiliki perusahaan. 8) Revenue Streams menggambarkan bagaimana organisasi memperoleh penghasilan berupa uang dari setiap customer segments. Aliran dana inilah yang membuat sebuah perusahaan tetap hidup atau survive. 9) Cost Structure, menggambarkan semua biaya yang muncul sebagai akibat dioperasikannya model bisnis ini guna mewujudkan value propotitions melalui channel, key resource, key activities yang tepat dan dapat diandalkan. Cara yang paling efektif adalah dengan mengkombinasikan analisa BMC dengan analisa SWOT (strengths, weaknesses, opportunities, threats)(Wardhanie \& Kumalawati, 2018).

Dalam mendesain Business Model Canvas, dapat dilakukan melalui langkah-langkah berikut (Wardhana, 2014): 1) menemukan sebuah ide bisnis, 2) mendeskripsikan latar belakang munculnya ide, 3) Identifikasi dan telusuri asumsi dari ide bisnis, 4) Lakukan pengujian atas asumsi business model tersebut terhadap calon konsumen bisnis dan dengan pemasok. Apabila terjadi kendala di lapangan, maka lakukan pivot (penyesuaian kembali business model yang telah dibuat dengan merubah salah satu atau beberapa komponen dari kesembilan bagian business model canvas, 5) Potret atau petakan model bisnis. Potret pada sembilan elemen Business Model Canvas didasarkan atas kondisi bisnis yang sebenarnya terjadi, 6) Lakukan analisis SWOT (Strength, Weakness, Opportunity, Threath). Analisis ini dilakukan pada masing-masing elemen. Sebagai contoh, pada elemen customer segments, kemampuan memilih customer segments yang memiliki populasi besar dan menguntungkan, dapat diklasifikasikan sebagai kekuatan organisasi. Sebaliknya, value propositions yang tidak dibutukan oleh suatu customer segments yang dibidik, dapat dikatakan sebagai kelemahan. Pasar yang berpotensi besar dan belum digarap dapat dikategorikan sebagai peluang. Di lain pihak, apabila pesaing baru muncul dan dapat mengancam keberadaan organisasi dapat dikategorikan sebagai kelemahan, dan 7) Lakukan penyempurnaan model bisnis dan atau buat prototipe. Hasil analisis SWOT kemudian digunakan untuk dua jenis tujuan. Pertama menyempurnakan business model yang ada saat ini, dan yang kedua melahirkan prototipe business model yang baru.

Hasil penelitian terdahulu menyebutkan penggunaan BMC sebagai model bisnis yang diterapkan pada berbagai bidang diantaranya perpustakaan dan konsultan interior, namun masing-masing memiliki kekuatan, kelemahan, peluang, dan ancaman sehingga diperlukan strategi bisnis yang tepat agar mampu memberikan pelayanan terbaik yang dapat menunjang pengembangan bisnis (Permatasari \& Maureen Nuradhi, 2020; Wardhanie \& Kumalawati, 2018). Kanvas model bisnis ini juga dirancangkan tidak hanya untuk keadaan pasar saat ini, tetapi juga untuk perkembangan perusahaan kedepannya agar dapat terus bersaing (Liemanto, 2016), dengan memanfaatkan fasilitas yang sudah dimiliki dan mengevaluasi kembali kesembilan elemen BMC sehingga dapat memenuhi kebutuhan pasar (Liemanto, 2016). Hasil penelitian lain yang menjadikan hotel di bali sebagai subjek penelitiannya menunjukkan bahwa perlu menambahkan beberapa strategi BMC seperti menjaga penerapan terkait CHSE (Cleanliness, Healthy, Safety, Environmental sustainability), memperbaiki ADR (Average Daily Rate) dengan terus meningkatkan service dan produk, renovasi kamar agar tampil fresh dengan mengganti wallpaper dan headboard, team sales perlu untuk lebih cermat memilih segmen pelanggan yang lebih mendapatkan pendapatan dibanding hanya volume pelanggan saja. Selain itu perlunya kerjasama manajemen atas dengan seluruh jajarannya agar menjadi dynamic saat diperlukan khususnya masa sulit menghadapi persaingan yang ketat (Wisnusanjaya \& Munir, 2021). Selain Bali, salah satu hotel di Bandung juga mengalami kendala okupansi rate yang cenderung stagnan sehingga membuat revenue mereka cenderung stagnan sehingga perlu dilakukan remodelling untuk model bisnis yang dijalankan yakni dengan menerapkan BMC yang memfokuskan pada salah satu elemen yakni revenue stream dengan mengembangkan Agen wisata dalam kota, Agen transportasi, Makanan ringan, Perlengkapan mandi, dan Layanan laundry yang tidak membutuhkan biaya yang besar sehingga feasible untuk dijalankan, selain 
itu menjalin kerja sama dengan agen travel untuk lebih mengenalkan hotel dan fasilitasnya (Sovia Pramudita, 2018). Industri lain yakni animasi mengembangkan model bisnisnya menggunakan BMC hasilnya menunjukkan bahwa Pengembangan business model canvas yang terbatasi oleh biaya pada perusahaan animasi kasat mata dengan pendekatan analisis SWOT dapat dikatakan layak untuk dijalankan. Hasil tersebut mengacu pada keseluruhan komponen analisis biaya yang membatasi setiap elemen pada business model canvas baru yang terbentuk, selain itu prospek kedepan terhadap bisnis ini masih cukup besar untuk dikembangkan karena berdasarkan analisis SWOT yang dilakukan menunjukan bahwa bisnis ini masih memiliki banyak peluang yang dapat dimanfaatkan dengan baik (Oktapriandi et al., 2017). Berdasarkan hasil penelitian yang telah dilakukan sebelumnya, maka perlu dilakukan analisis SWOT untuk memetakan kedalam sembilan elemen yang terdapat pada bisnis model canvas.

Oleh karena itu tujuan penelitian ini adalah merancang model bisnis Syahida Inn dengan memetakan BMC Syahida Inn saat ini serta Strenght Weakness Opportunity Threat (SWOT) sebagai dasar analisisnya.

\section{METODE PENELITIAN}

Penelitian dilakukan di Syahida Inn yang berlokasi di Jalan Kertamukti, Kampus II UIN Syarif Hidayatullah Jakarta, Ciputat Tangerang Selatan. Penelitian dilakukan pada rentang waktu Januari-Juni 2020. Penelitian ini dilakukan dengan menggunakan metode deskriptif-kualitatif melalui pendekatan studi kasus. Studi kasus sebagai metodologi empiris yang sesuai untuk melakukan penelitian yang berkaitan dengan partisipasi masyarakat karena menggunakan berbagai metode penelitian, mulai dari wawancara, observasi, pengumpulan data sekunder (Bhaskara, 2017). Definisi lain dari studi kasus sebagai eksplorasi sistem yang dibatasi oleh kasus (atau beberapa kasus) dari waktu ke waktu, melalui pengumpulan data rinci yang melibatkan banyak sumber yang kaya informasi dalam suatu konteks (Creswell, 1998). Pendekatan studi kasus merupakan jenis pendekatan yang digunakan untuk menyelidiki dan memahami sebuah kejadian atau masalah yang telah terjadi dengan mengumpulkan berbagai macam informasi yang kemudian diolah untuk mendapatkan sebuah solusi agar masalah yang diungkap dapat terselesaikan. Penelitian ini akan mengkaji lebih dalam terkait perkembangan bisnis yang dialami oleh Syahida Inn terutama pada saat pandemic Covid-19, kemudian akan dirumuskan sebuah solusi dalam bentuk strategi pengembangan usaha yang berkelanjutkan.

Data yang digunakan penelitian ini adalah data primer dan data sekunder. Data primer diperoleh dari hasil wawancara dengan informan penelitian. 11 (sebelas) informan yang digunakan dalam penelitian berasal dari internal Syahida Inn dan Kampus UIN Syarif Hidayatullah Jakarta serta 5 (lima) informan dari eksternal Syahida Inn yakni dari Balai Diklat Keagamaan DKI Jakarta, Direktorat Zakat dan Wakaf, Biro Keuangan dan BMN Kementerian Agama. Data sekunder diperoleh dari pihak lain yang berupa dokumen, buku referensi, dan berita/artikel dari internet. Teknik pengumpulan data yang digunakan dalam penelitian ini adalah:

1. Wawancara dan kuesioner, teknik wawancara dilakukan dalam bentuk diskusi dan komunikasi dua arah dengan menyusun daftar pertanyaan sebelumnya. Wawancara dilakukan terhadap 11 (sebelas) informan yang digunakan dalam penelitian ini berasal dari internal Syahida Inn dan Kampus UIN Syarif Hidayatullah Jakarta serta 5 (lima) informan dari eksternal Syahida Inn yakni dari Balai Diklat Keagamaan DKI Jakarta, Direktorat Zakat dan Wakaf, Biro Keuangan dan BMN Kementerian Agama.

2. Observasi melalui pengamatan dan pencatatan terhadap instansi yang terkait dalam penelitian dan objek sasaran yang diteliti. Pengamatan dan pencatatan dilakukan terhadap Syahida Inn, seperti laporan pendapatan per tahun. 
3. Focus Group Discussion, yaitu dilakukan terhadap internal manajemen Syahida Inn dan beberapa pihak luar yang memiliki pengetahuan terkait strategi pengembangan model bisnis, diantaranya pegawai Syahida Inn, para Kepala Bagian termasuk Kepala Bagian Perencanaan UIN Syarif Hidayatullah Jakarta.

4. Dokumentasi yang diperoleh dalam bentuk dokumen yang berasal dari hasil wawancara, observasi, dan data sekunder.

Perancangan model bisnis Syahida Inn dilakukan melalui proses analisis deskriptif atas kondisi yang ada di Syahida Inn. Berdasarkan teknik pengumpulan data yang telah dibahas pada paragraph sebelumnya, maka data yang telah terkumpul akan diolah dan dianalisa. Selanjutnya dilakukan identifikasi terhadap sembilan elemen Business Model Canvas (BMC). Kesembilan elemen tersebut yaitu customer segments, value propositions, channels, customer relationships, revenue streams, key resources, key activities, key partnerships, dan cost structures. Setelah proses identifikasi elemen BMC dilakukan, setiap elemen pada BMC Syahida Inn dinilai secara mendalam dengan analisis SWOT untuk mengetahui kekuatan, kelemahan, peluang dan ancaman yang dimiliki oleh Syahida Inn selaku unit bisnis UIN Syarif Hidayatullah Jakarta. Analisis SWOT akan membantu perusahaan dalam menemukan strategi yang tepat dari hasil analisa yang telah dilakukan (Rangkuti, 2006). Pemilihan BMC sebagai model bisnis diharapkan mampu menjadi alternatif strategi Syahida Inn selaku unit bisnis pada Badan Layanan Umum UIN Syarif Hidayatullah yang mampu mengoptimalkan potensi menghasilkan pendapatan untuk meningkatkan Pendapatan Negara Bukan Pajak (PNBP) yang selanjutnya akan menjadi pendapatan BLU UIN Syarif Hidayatullah. Beberapa industri juga telah mengaplikasikan BMC untuk mengembangkan bisnisnya seperti yang disebutkan pada hasil beberapa penelitian terdahulu. Selain memiliki elemen yang lebih detail juga didukung analisis SWOT yang akan memudahkan Syahida Inn dalam menganalisa berbagai aspek seiring dengan perubahan perubahan yang terus berkembang dan terjadi. Analisis ini menggambarkan strategi bisnis dengan analisis faktor internal (kekuatan dan kelemahan) dan analisis faktor eksternal (peluang dan ancaman) yang dipahami oleh pihak internal (Syahida Inn) dan bagian perencanaan yang bertanggungjawab atas perkembangan dan kemajuan unit unit yang berada dibawah UIN Syarif Hidayatullah. Selain memahami visi, misi dan tujuan unit organisasi juga memiliki kemampuan dalam Menyusun strategi bisnis. Pemilihan BMC sebagai model bisnis dapat menganalisis faktor kekuatan, kelemahan, peluang dan ancaman pada Syahida Inn dengan mengidentifikasi sembilan elemen BMC dan SWOT sebagai Langkah awal dalam merancang model bisnis Syahida Inn di masa yang akan datang.

\section{HASIL DAN PEMBAHASAN}

Kondisi BMC saat ini pada Syahida Inn ditentukan berdasarkan hasil wawancara dengan narasumber yang terdiri dari 6 (enam) orang Staf Senior Syahida Inn, para Kepala Bagian (eselon III) di UIN Syarif Hidayatullah Jakarta. Sementara dari eksternal Syahida Inn wawancara dilakukan kepada pejabat pada Biro Keuangan dan BMN Kementerian Agama, Balai Diklat DKI Jakarta, Direktorat Zakat dan Wakaf, serta beberapa customer tetap Syahida Inn. Hasil wawancara berupa informasi yang akurat didapat dari berbagai pertanyaan terkait sembilan elemen BMC. Narasumber tersebut dinilai memiliki kapasitas untuk memberikan informasi yang relevan yang mendukung proses identifikasi sembilan elemen dalam business model canvas (BMC) sebagai model bisnis Syahida Inn saat ini. Dalam wawancara yang dilakukan kepada informan terkait Customer Segment, dimana salah satu narasumber mengatakan "Syahida Inn mempromosikan diri melalui Media Sosial dan ekerja sama dengan pihak Traveloka sehingga banyak customer baru yang tertarik dengan Syahida Inn. Tidak sedikit pula customer lama yang merekomendasikan Syahida Inn baik kepada saudara, teman dan kerabat lainnya". Dari hal ini dapat disimpulkan bahwa segmen Syahida Inn banyak terfokus pada pelanggan individu, sementara 
pelanggan instansi masih belum banyak. Selanjutnya berkenaan dengan Value proposition yang membahas mengenai produk jasa/fasilitas yang ditawarkan oleh syahida inn, dimana narasumber mengatakan bahwa "Penginapan / kamar yang terdiri dari Deluxe \& VIP Room include Breakfast, Ruang Meeting Standar dengan kapasitas 20 s.d 50 Org, Ruang Auditorium untuk Seminar, Workshop, Perpisahan dll, Ruang Serbaguna untuk kegiatan Resepsi Pernikahan maupun Khitanan, Paket meeting untuk kegiatan pelatihan dll, Fitness Center \& Café" Kemudian berkaitan dengan keunggulan model jasa/fasilitas yang ada di Syahida Inn? Jawab: Proses Booking mudah, Harga yang terjangkau, Fasilitas lengkap, Lokasi strategis \& Aman, Parkir Luas, Pegawai yang Ramah dan Sopan". Channels "Bagaimanakah saluran distribusi yang sudah dilakukan oleh Syahida Inn? Jawab: Syahida Inn memiliki jalur distribusi di berbagai lini yaitu melalui Media social, Traveloka, Travel Bloggers, Website dan dari mulut ke mulut. Bagaimanakah strategi offline Syahida Inn agar strategi layanan bisa diketahui oleh customer? Jawab: Syahida Inn memiliki tim marketing \& Front Office yang ramah dan setelah customer memakai jasa/fasilitas Syahida Inn selalu kami mengingatkan untuk kembali lagi dan memberikan brosur kepada calon-calon customer. Kemudian tim selalu menghubungi customer yang menjadi langganan Syahida Inn untuk memakai jasa/fasilitas Syahida Inn kembal". Costumer Relationship "Bagaimanakah cara Syahida Inn menjaga hubungan dengan para Custumer? Jawab: Tim marketing maupun front Office sering menghubungi customer baik yang baru maupun yang lama. Sehingga, customer merasa dibutuhkan dan dilayani dengan baik. Apakah Syahida Inn memiliki data lengkap / database terkait customer? Jawab: Database yang digunakan ialah Nomor kontak Customer yang masih aktif beserta nama Instansi yang tersimpan didalam Aplikasi Panel Syahida Inn". Revenue Stream "Produk jasa/fasilitas mana yang paling menguntungkan bagi Syahida Inn? Jawab: Pendapatan yang sangat menguntungkan bagi Syahida inn yaitu Penyewaan Ruang Auditorium maupun Ruang Serbaguna. Bagaimana cara SYAHIDA INN dalam menentukan harga? Jawab: Syahida Inn memiliki tarif layanan sesuai dengan SK Rektor UIN Syarif Hidayatullah Jakarta. Untuk kegiatan tertentu harga ditentukan oleh pihak management Syahida Inn". Key Activities "Bagaimanakah stuktur pembagian jobdesc di Syahida Inn? Jawab: Jobdesc dibagi oleh pihak manajemen Syahida Inn sesuai dengan Posisi yang ditempati tiap-tiap pegawai". Key Resources "Apa aja asset yang dimiliki SYAHIDA INN? Jawab: Gedung, AC, TV, Mobil, Peralatan kantor". Key Partnership "Siapa saja yang menjadi mitra SYAHIDA INN? Jawab: Untuk saat ini yang menjadi mitra utama Syahida Inn adalah Traveloka dan Café Syahida Inn". Cost Structure "Apa saja yang menjadi biaya tetap dari operasional SYAHIDA INN? Gaji Karyawan, Listrik, Air, Internet, kebutuhan sehari-hari tamu, dll".

Berdasarkan hasil wawancara secara keseluruhan, maka Identifikasi sembilan elemen BMC pada Syahida Inn saat ini adalah pada elemen customer segments, tamu individu dan instansi pemerintah baik Kementerian Agama maupun Kementerian lainnya. Value propositions yang ditawarkan Syahida Inn adalah kemudahan, keramahan, kenyamanan memesan, keberadaan ruang meeting, ruang auditorium, ruang serbaguna, fitness center dan cafe, penerapan kaidah syariah, serta lokasi strategis diantara Jakarta Selatan dan Tangerang Selatan. Customer relationships yang berlangsung saat ini pelayanan ramah dalam wujud lisan maupun melalui pesan elektronik seperti whatsapp serta salam sapa via telepon dari front office kepada customer. Channels Syahida Inn yang dipakai adalah social media (instagram, twitter, facebook), website, travel blogger, YouTube, brosur/surat dan word of mouth (mulut ke mulut) sedangkan channels penghimpunan Syahida Inn menggunakan online travel agent Traveloka. Revenue streams Syahida Inn saat ini diperoleh dari biaya sewa kamar, penyewaan ruang meeting, penyewaan ruang serbaguna, biaya langganan fitness centre dan penjualan di cafe. Key resources pada Syahida Inn adalah aset fisik berupa gedung kantor, kendaraan dan branding UIN Syarif Hidayatullah Jakarta. Key activities yang ada saat ini adalah kegiatan pelayanan, memanfaatkan jaringan/networking untuk mendapatkan customer, memperbaiki data base, dan aktif 
pada akun media sosial. Key partnership saat ini pada Syahida Inn adalah dengan para wedding organizer, catering supplier, Traveloka, dan Travel Blogger. Pada elemen cost structure Syahida Inn adalah biaya gaji pegawai, biaya operasional dan pemeliharaan, serta biaya promosi/marketing.

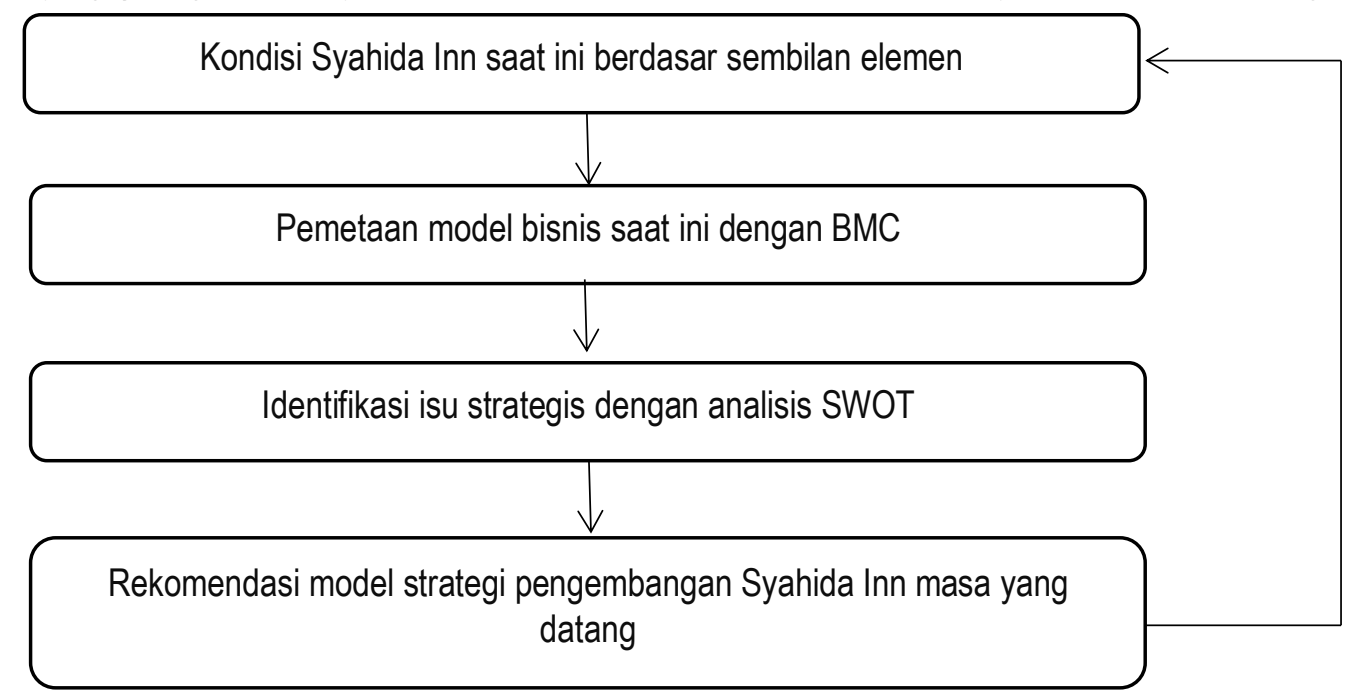

Gambar 3 Kerangka Pemikiran Konseptual

Tabel 2 Identifikasi Business Model Canvas (BMC) Syahida Inn Saat In

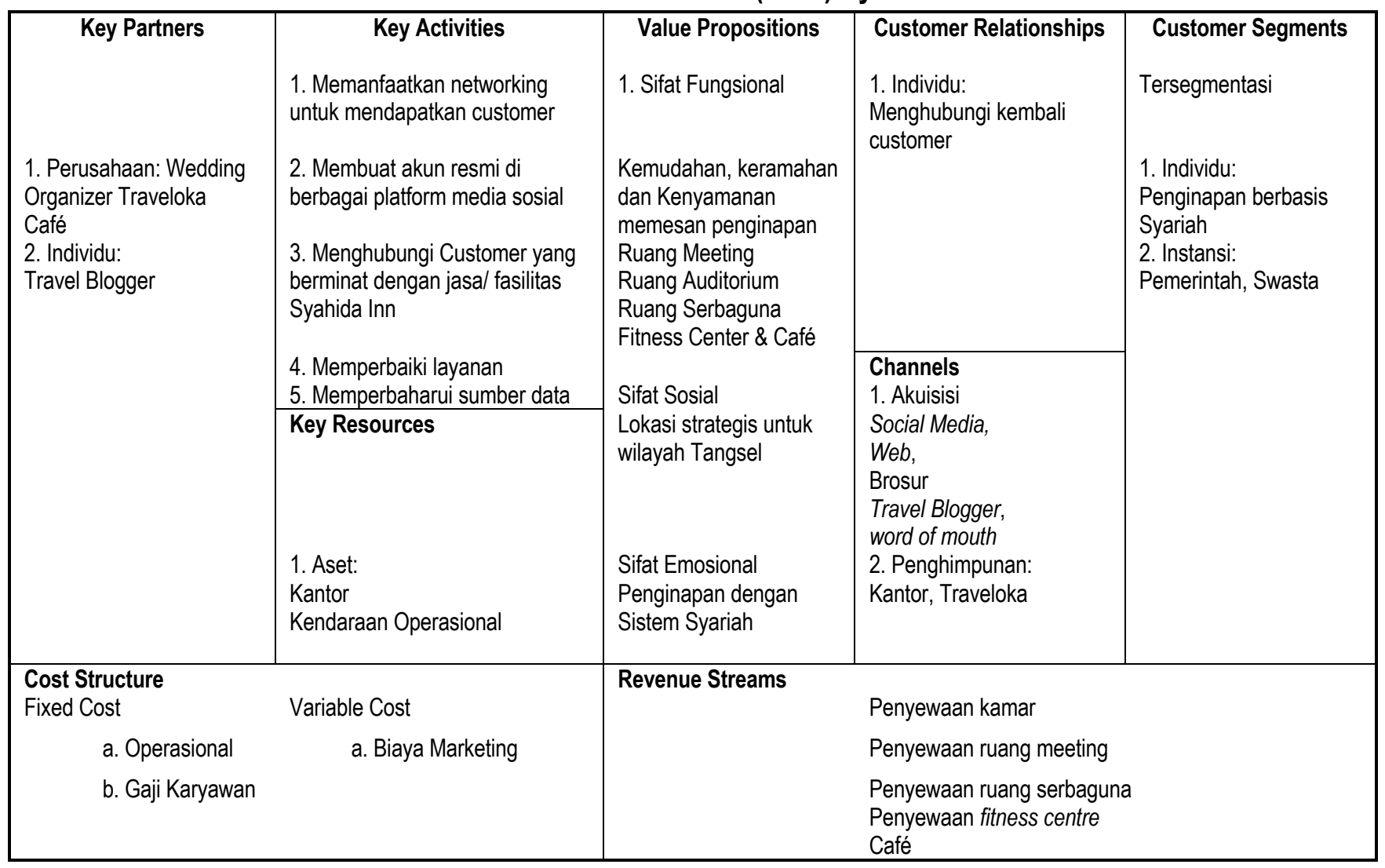

Sumber: Data Primer yang diolah 
Berdasarkan gambar diatas dan hasil analisa dari wawancara yang telah dilakukan, Syahida Inn telah memetakan kesembilan elemen BMC untuk menguatkan strategi model bisnis yang sudah dijalankan sebelumnya dengan mengevaluasi kembali hal hal yang belum dimaksimalkan sehingga dapat termanfaatkan secara optimal guna menghasilkan pendapatan yang lebih besar.

\section{Identifikasi SWOT}

Tahap selanjutnya adalah melakukan identifikasi SWOT saat ini, pada setiap elemen business model canvas (BMC) dengan analisis Strength Weakness Opportunity Threat (SWOT) untuk mengetahui kekuatan, kelemahan, ancaman dan peluang dari setiap elemen BMC Syahida Inn. Berdasarkan hasil wawancara, pengisian kuisioner dan observasi lapangan, hasil identifikasi SWOT dapat dilihat pada tabel dibawah ini:

Tabel 3 Hasil analisis SWOT pada BMC Syahida Inn

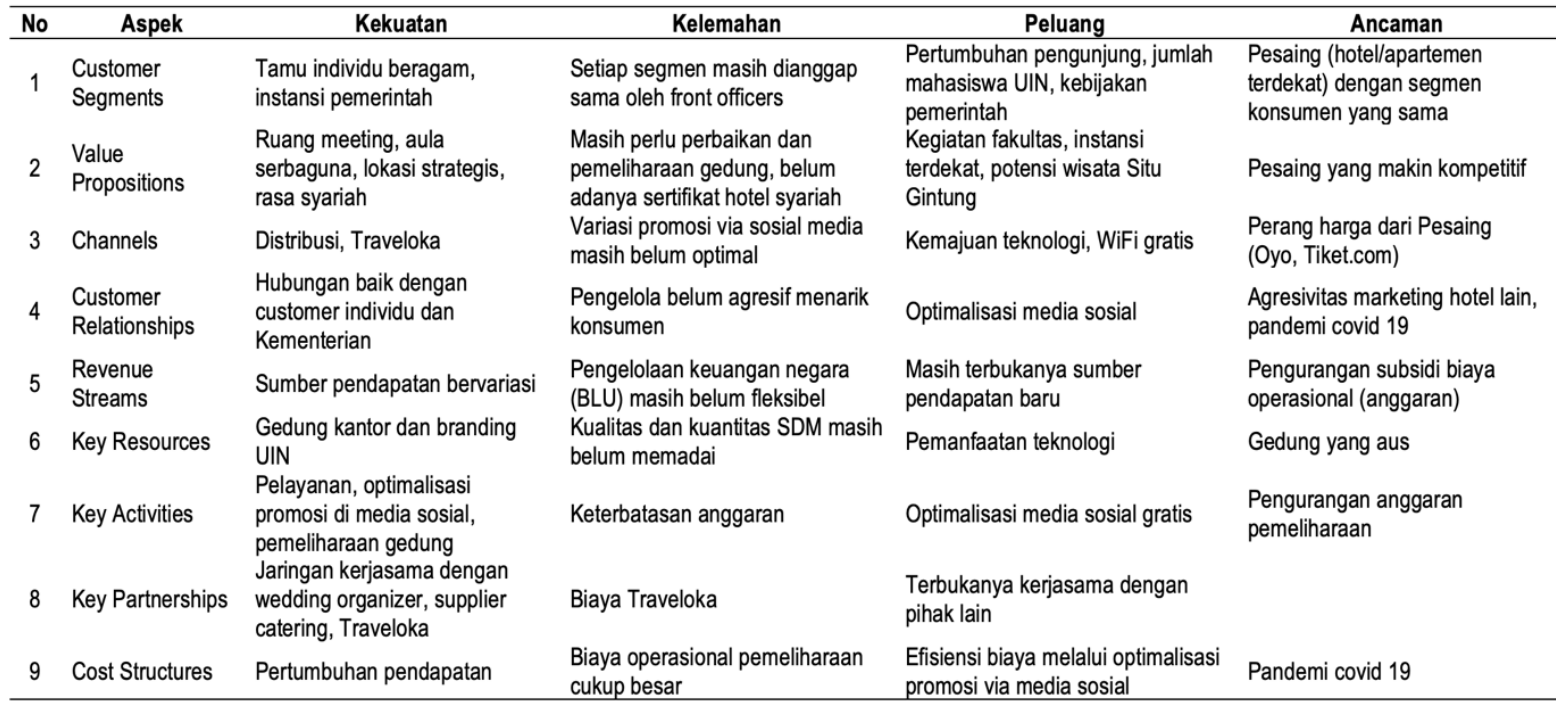

Sumber: Data Primer yang diolah

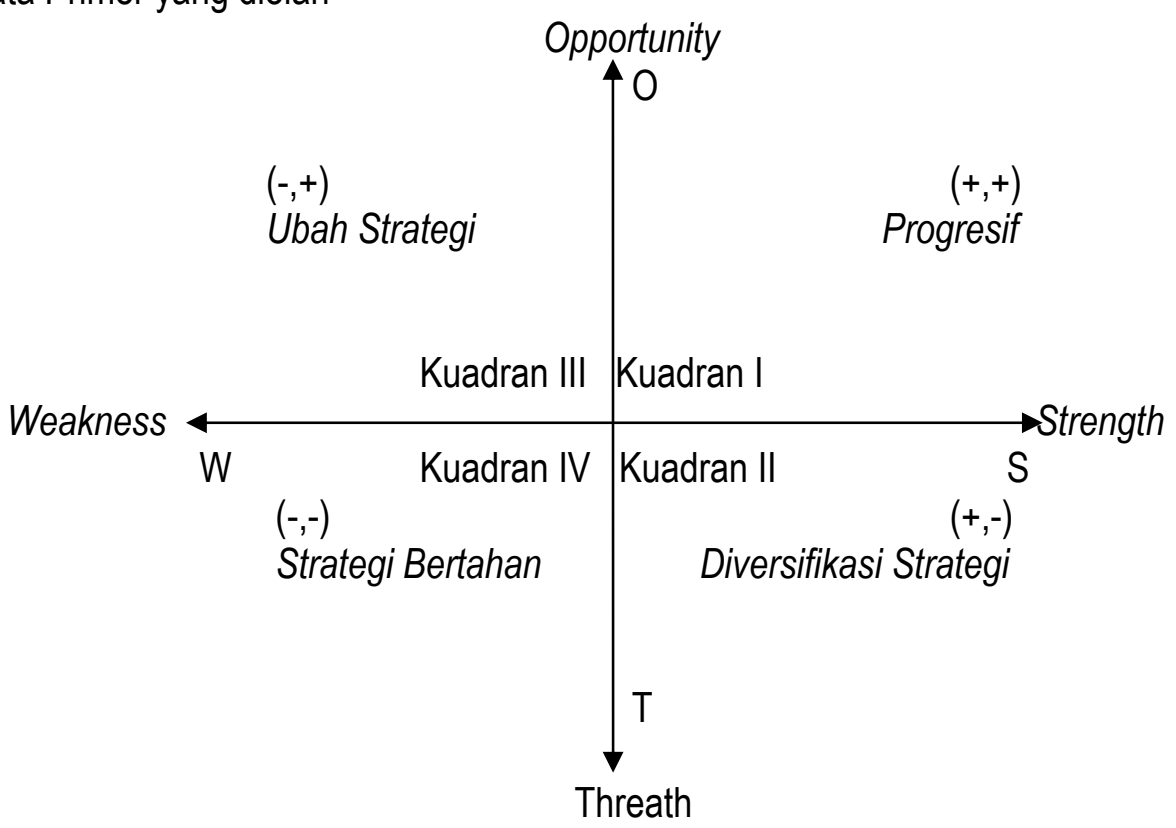

Gambar 4 SWOT 
Berdasarkan hasil analisis SWOT yang telah dipetakan, maka dilakukanlah pembobotan untuk mengetahui posisi Syahida Inn. Pembobotan yang sudah dilakukan terhadap kekuatan, kelemahan, peluang, dan ancaman diketahui posisi Syahida Inn berada dalam Kuadran I. Posisi ini menandakan sebuah organisasi yang kuat dan berpeluang. Rekomendasi strategi yang diberikan dalam menjalankan bisnis adalah progresif, artinya organisasi dalam kondisi prima dan mantap sehingga sangat dimungkinkan untuk terus melakukan ekspansi, memperbesar pertumbuhan dan meraih kemajuan secara maksimal.

Dalam kondisi ini, strategi progresif yang harus Syahida Inn lakukan sebagai sebuah organisasi sebaiknya fokus pada 3 (tiga) hal berikut ini demi pencapaian tujuannya yakni:

a. Penetrasi Pasar (market penetration)

Strategi ini bertujuan untuk mencari pelanggan agar mau menggunakan jasa layanan dari Syahida Inn, yang bisa dilaksanakan melalui iklan/promosi dan membuat strategi harga yang sesuai dengan target pasar yang dituju. Cara untuk melakukan strategi ini dengan menggencarkan unsur bauran pemasaran (marketing mix), yakni peningkatan promosi khususnya kepada instansi dibawah Kementerian Agama RI, melakukan kerjasama dengan biro perjalanan (tour travel) dengan skema bagi hasil atau komisi (fee) bagi biro perjalanan yang memberikan tamunya menjadi customer Syahida Inn, atau dapat juga dengan memberikan potongan harga (diskon) kepada para tamu mengantisipasi kelesuan pengunjung pada low season. Hal ini dilakukan untuk lebih memperkuat elemen pada BMC khususnya key partners, key activities, costumer segments, channels dan cost structure. Meningkatkan Kerjasama dengan berbagai mitra, menarik pelanggan dengan pemberian diskon merupakan bentuk action syahida inn dalam menghadapi rate pengunjung yang tidak stabil sehingga dapat memperkuat posisi syahida inn dalam mempertahankan bisnis bidang perhotelan dimasa pandemi 19 ini.

b. Pengembangan Pasar (market development)

Strategi ini berupaya meningkatkan pangsa pasar untuk produk atau jasa yang ada di Syahida Inn saat ini melalui upaya-upaya pengenalan produk Syahida Inn ke wilayah geografis baru, misalnya ke wilayah luar Jakarta seperti Kabupaten Tangerang, Kota Tangerang, Serang atau daerah lain di sekitar Provinsi Banten. Pada pengembangan pasar strategi yang digunakan yakni memperluas target pasar dan mempromosikan syahida inn. Hal ini dilakukan untuk memperkuat element BMC khususnya value proposition dan customer relationships, dengan mempromosikan Syahida inn yang bergerak di industri perhotelan akan memudahkan masyarakat dalam mencari penginapan sehingga dapat memberikan solusi pada waktu yang cepat dan tepat.

c. Pengembangan Produk (product development)

Strategi ini dapat dijalankan untuk meningkatkan penjualan dengan cara memperbaiki atau memodifikasi produk yang ada saat ini dengan tujuan untuk mendorong tamu dalam memanfaatkan semua fasilitas yang tersedia di Syahida Inn agar tamu memperpanjang masa menginap dan menginformasikan kepada keluarganya, rekan kerja, relasi lainnya tentang fasilitas yang tersedia di Syahida Inn. Strategi ini juga dapat dilakukan dengan cara meningkatkan kualitas produk layanan yang diharapkan dapat meningkatkan pendapatan Syahida Inn seperti menambah alat-alat fitness atau mengganti yang usang dengan peralatan yang baru, mengganti karpet auditorium dan panggung, mendesain kembali ruang VIP, ruang meeting dengan nuansa yang lebih modern, atau memperluas area aula serbaguna sehingga dapat digunakan untuk acara yang jauh lebih besar. Hal ini dilakukan untuk mendukung elemen BMC antara lain key resource, revenue streams, value proposition dan cost structure. Dalam pengembangan produk Syahida inn akan mengoptimalkan fasilitas yang ada dan melakukan penambahan fasilitas dalam memenuhi kebutuhan pelanggan sehingga seluruh kebutuhan custumer dapat tersedia karena memiliki fasilitas yang sangat lengkap. 


\section{PENUTUP}

Strategi bisnis yang dijalankan oleh Syahida Inn sudah cukup baik terbukti dengan terjadinya peningkatan pendapatan Syahida Inn yang menjadi Pendapatan Negara Bukan Pajak (PNBP) BLU UIN Syarif Hidayatullah Jakarta dari sebelumnya pada kisaran Rp. 2 Milyar menjadi Rp. 3,2 Milyar pada tahun 2019. Hal ini tidak terlepas dari strategi bisnis dengan beberapa pendekatan yakni:

a. Membuat target segmentasi customer pada tamu individu dan tamu corporate.

b. Menjaga hubungan dengan customer melalui pesan whatsapp yang berisi cuapan terima kasih atau program promosi baru tentang Syahida Inn.

c. Memperbanyak kanal digital seperti bekerjasama dengan online travel agent Traveloka dan optimalisasi akun media sosial milik Syahida Inn.

Berdasarkan hasil business model canvas (BMC) yang telah disusun, Syahida Inn dalam proses pencapaian visi dan misinya memberikan nilai lebih (value) berupa kemudahan, keramahan, strategisnya lokasi, serta nuansa syariah kampus UIN Syarif Hidayatullah Jakarta kepada customernya baik customer individu maupun customer corporate. Value tersebut disampaikan melalui jalur distribusi (channel) baik melalui akun sosial media yang dimiliki, website, brosur, word of mouth, maupun melalui jejaring instansi pemerintah dibawah Kementerian Agama RI atau melalui online travel agent Traveloka.

Gedung Syahida Inn, mesin dan peralatan serta kendaraan yang dimiliki menjadi key resources Syahida Inn dalam mendukung aktivitas utama (key activities) Syahida Inn yakni optimalisasi pemanfaatan jaringan (networking) untuk mendapatkan customer baru dan aktivitas promosi lainnya. Pendapatan utama Syahida Inn (revenue streams) didominasi oleh penyewaan kamar (akomodasi), penyewaan ruang meeting, ruang serbaguna diteruskan oleh pendapatan dari cafe/resto dan penyewaan ruang fitness.

Elemen cost structure dalam BMC Syahida Inn terbagi menjadi dua yakni fixed cost yang terdiri dari biaya operasional/pemeliharaan dan biaya gaji/tunjangan karyawan, dan variable cost yang didominasi oleh biaya pemasaran (marketing dan promosi).

Hasil analisis SWOT, berdasarkan pembobotan yang sudah dilakukan terhadap kekuatan, kelemahan, peluang, dan ancaman diketahui posisi Syahida Inn berada dalam Kuadran I. Posisi ini menandakan sebuah organisasi yang kuat dan berpeluang. Rekomendasi strategi yang diberikan adalah progresif, artinya organisasi dalam kondisi prima dan mantap sehingga sangat dimungkinkan untuk terus melakukan ekspansi, memperbesar pertumbuhan dan meraih kemajuan secara maksimal. Dalam kondisi strategi progresif, Syahida Inn sebagai sebuah organisasi sebaiknya fokus pada 3 (tiga) hal berikut ini demi pencapaian tujuannya yakni penetrasi pasar (market penetration), pengembangan pasar (market development), dan pengembangan produk (product development).

\section{Daftar Pustaka}

Alexander Osterwalder, Y. P. (2013). Business Model Generation: A Handbook for Visionaries, Game Changers, and Challengers. John Wiley \& Sons.

Bhaskara, G. I. (2017). Penggunaan metedologi studi kasus filosofi, metodologi dan metode.

Creswell, J. . (1998). Qualitative inquiry and research design: choosing among five traditions. Sage.

Diayudha, L. (2020). Industri Perhotelan Di Indonesia Pada Masa Pandemi Covid-19: Analisis Deskriptif. Journal FAME: Journal Food and Beverage, Product and Services, Accomodation Industry, Entertainment Services, 3(1). https://doi.org/10.30813/fame.v3i1.2166

Juliani, H. (2018). Eksistensi Badan Layanan Umum Sebagai Penyelenggara Pelayanan Publik. Administratif Law and Governance Journal, 1(2), 149-164. https://doi.org/10.14710/alj.v1i2.149-164 
Liemanto. (2016). Perancangan Business Model Pada Hotel Sunrise di Labuan Bajo, Flores-NTT. Agora, Manajemen Bisnis, Universitas Kristen Petra, 4(1), 159-165.

Oktapriandi, D., Purnomo, M. R. A., \& Parkha, A. (2017). Analisis pengembangan model bisnis pada industri animasi menggunakan business model canvas yang terbatasi biaya. Teknoin, 23(3), 195210. https://doi.org/10.20885/teknoin.vol23.iss3.art2

Permatasari, L., \& Maureen Nuradhi, L. (2020). Analisis Business Model Canvas pada Perusahaan Konsultan Interior X. SEMINAR NASIONAL ENVISI 2020: INDUSTRI KREATIF, 175-186. https://www.uc.ac.id/envisi/wp-content/uploads/publikasina/ENVISI-2020-p175-Laurenita Permatasari, Laurensia Maureen Nuradhi-Analisa Business Model Canvas pada Perusahaan Konsultan Interior X.pdf

Rangkuti, F. (2006). Teknik Mengukur dan Strategi Meningkatkan Kepuasan Pelanggan. PT. Gramedia Pustaka Utama.

Sovia Pramudita, A. (2018). Formulasi Model Bisnis Hostel di Bandung dengan Pendekatan Value Chain dan Business Model Canvas (Studi Kasus: Pinisi Backpacker). ISEI Business and Management Review, II(1), 32-38. https://doi.org/10.36217/ibmr.v2i1.44

Wardhana, A. (2014). Business Model Cnavas Penerapannya Pada Industri Jasa Pertambangan Batubara di Indonesia (S. Sonjaya (ed.)). PT. Karya Manunggal Lithomas.

Wardhani, A. P. (2017). Buku ajar model bisnis. PT. Revka petra media.

Wardhanie, A. P., \& Kumalawati, D. (2018). Analisis business model canvas pada perpustakaan Institut Bisnis dan Informatika Stikom Surabaya dalam meningkatkan kualitas perguruan tinggi. Berkala IImu Perpustakaan Dan Informasi, 14(2), 124. https://doi.org/10.22146/bip.32247

Wisnusanjaya, A., \& Munir, N. S. (2021). Analisis Model Bisnis Hotel XYZ. Journal of Emerging Business Management and Entrepreneurship Studies, 1(2021), 1-20.

Peraturan Pemerintah Nomor 23 Tahun 2005 Jo Peraturan Pemerintah Nomor 74 Tahun 2012 Tentang Pengelolaan Keuangan Badan Layanan Umum. 